\title{
Is the B757 Really a "Heavy” Aircraft?
}

\author{
James N. Hallock ${ }^{1}$ and Melanie A. Soares ${ }^{2}$ \\ US DOT RITA John A. Volpe National Transportation Systems Center, Cambridge, MA 02142
}

In July 1996, a new wake vortex category was created for the B757 which placed it between revised Large and Heavy categories. Shortly thereafter, the B757-300, stretched version of the B757-200, was placed in service and soon was treated by Air Traffic Control as a Heavy aircraft due to its maximum certificated takeoff weight. This study examines the behavior of vortices from both aircraft during approach/landing operations and shows little difference between the vortices of the two B757 series. In fact, both measurements and theory indicate that B757-300 vortices decay somewhat faster than B757-200 vortices. Therefore, the B757-300 is being penalized by unneeded increased wake vortex spacing during approach/landing operations.

\section{Nomenclature}

$\begin{array}{ll}b & =\text { wingspan } \\ b_{0} & =\text { initial vortex spacing, } \mathrm{Kb} \\ \mathrm{C}_{\mathrm{L}} & =\text { lift coefficient } \\ g & =\text { acceleration of gravity } \\ K & =\text { wing loading factor } \\ k & =1 /(1 / 2) \mathrm{SC}_{\mathrm{L}} \\ L & =\text { lift } \\ M & =\text { mass } \\ q & =\text { dynamic pressure } \\ r & =\text { distance from vortex center } \\ S & =\text { wing platform area } \\ T & =\text { non-dimensional time } \\ v(r) & =\text { vortex velocity profile } \\ V & =\text { airspeed } \\ \Gamma & =\text { circulation } \\ \rho & =\text { air density }\end{array}$

\section{Introduction}

Wake vortex separation standards define the minimum distance between lead and following landing aircraft to ensure the following aircraft will land safely without experiencing a hazardous wake vortex encounter. Smaller aircraft following behind a larger aircraft are more susceptible to the circulation or strength of the wake of the larger aircraft, and so the longitudinal or inter-aircraft distance is increased for the smaller aircraft. Current separation standards are based on the maximum gross certificated takeoff weight of the lead and following aircraft.

The B757-200 was certified by the FAA in December 1982 and placed in service on January 1, 1983. The B757 was categorized as a Large aircraft according to the separation standard defined in November $1975^{1}$ where the weight cut-off for Heavy aircraft was 300,000 lbs (the gross certificated takeoff weight). Following a series of accidents $^{2,3}$ and incidents involving the B757 as the leading aircraft, the landing separation standards were modified in July 1996 by creating a new category just for the B757. The new weight cut-off for Heavy aircraft was set at 255,001 lbs as shown in Table 1. In the Fall of 1996, a stretch version of the B757-200 was introduced: the B757300 series, which had the same wingspan as the B757-200 (124.8 ft). Due to the extended fuselage, the maximum takeoff weight $(270,000 \mathrm{lbs})$ was no longer within the weight limits for the B757 class and so the B757-300 was

\footnotetext{
${ }^{1}$ Senior Technical Expert for Air and Space Transportation Safety, RTV-5B, Senior Member AIAA.

${ }^{2}$ Engineer, Advanced Communication, Navigation and Surveillance Technologies Division, RTV-4A.
} 
classified as a Heavy aircraft increasing the separation distance of following aircraft by 1 nautical mile, which in turn adversely impacts airport capacity.

\begin{tabular}{|c|c|c|c|c|c|}
\hline \multicolumn{2}{|c|}{ Leading Aircraft } & \multicolumn{4}{c|}{ Following Aircraft } \\
\hline Class & Weight (Ibs) & Heavy & B757 & Large & Small \\
\hline Heavy & $255,001+$ & $4 \mathrm{nmi}, 107 \mathrm{~s}$ & $5 \mathrm{nmi}, 133 \mathrm{~s}$ & $5 \mathrm{nmi}, 133 \mathrm{~s}$ & $6 \mathrm{nmi}, 160 \mathrm{~s}$ \\
\hline B757 & $220,000-250,000$ & $4 \mathrm{nmi}, 107 \mathrm{~s}$ & $4 \mathrm{nmi}, 107 \mathrm{~s}$ & $4 \mathrm{nmi}, 107 \mathrm{~s}$ & $5 \mathrm{nmi}, 133 \mathrm{~s}$ \\
\hline Large & $41,001-255,000$ & $3 \mathrm{nmi}, 80 \mathrm{~s}$ & $3 \mathrm{nmi}, 80 \mathrm{~s}$ & $3 \mathrm{nmi}, 80 \mathrm{~s}$ & $4 \mathrm{nmi}, 107 \mathrm{~s}$ \\
\hline Small & $0-41,000$ & $3 \mathrm{nmi}, 80 \mathrm{~s}$ & $3 \mathrm{nmi}, 80 \mathrm{~s}$ & $3 \mathrm{nmi}, 80 \mathrm{~s}$ & $3 \mathrm{nmi}, 80 \mathrm{~s}$ \\
\hline
\end{tabular}

Table 1: Current Separation Standards

The Volpe Center under the joint FAA/NASA Wake Turbulence Research Program has established many test sites to study wake vortex transport for various aircraft types. In San Francisco (SFO), a test site was established and operated from February 2000 to May 2001 and again from September 2001 to October 2002. At SFO, the test site was selected to study arrivals on Runways $28 \mathrm{~L}$ (left) and 28R (right). Propeller anemometers mounted on 3-ft poles in a three parallel Windline configuration determined the location of wake vortices. Each Windline was oriented perpendicular to the closely-spaced parallel runways with the anemometer poles placed 25 feet apart and oriented to measure crosswind. For reference, the crosswind was termed positive if blowing from the pilot's left-hand side to the right. Wake vortex data shown herein was generated near the ground (the aircraft were about $65 \mathrm{ft}$ above the ground) and collected on Windline 1 at SFO. Windline 1 was $1250 \mathrm{ft}$ long and was located perpendicular to the ends of runways $28 \mathrm{~L}$ and 28R. A photograph of the anemometer poles on Windline 1 as well as an overhead layout of the SFO test site are shown in Figs. 1 and 2, respectively. Due to the length of the Windline, an occasional vortex was transported past the last anemometer pole. To ensure no bias in the age of the track, only tracks that terminated on the Windline were used in this study.

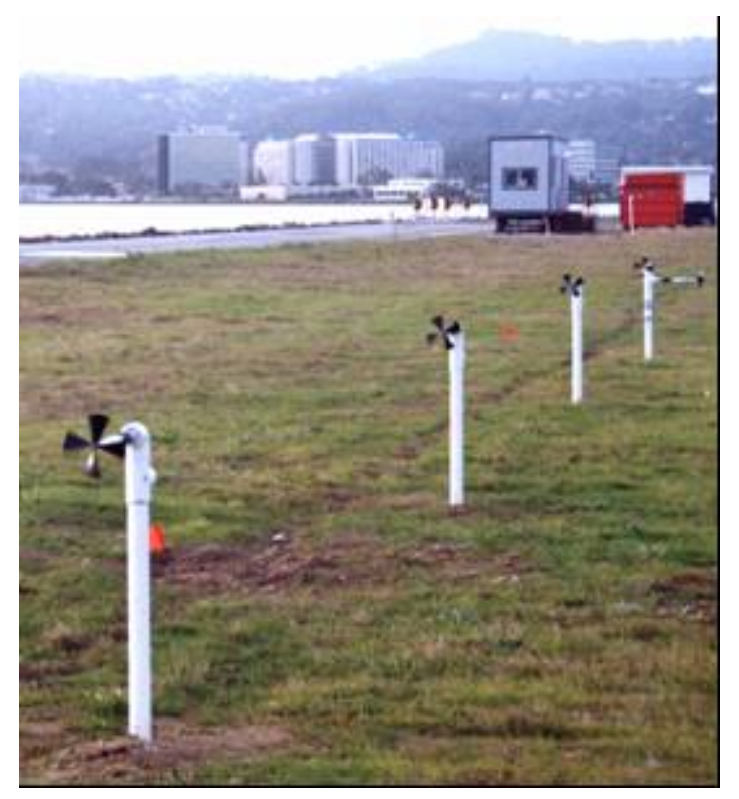

Figure 1: Anemometer windline at SFO. 


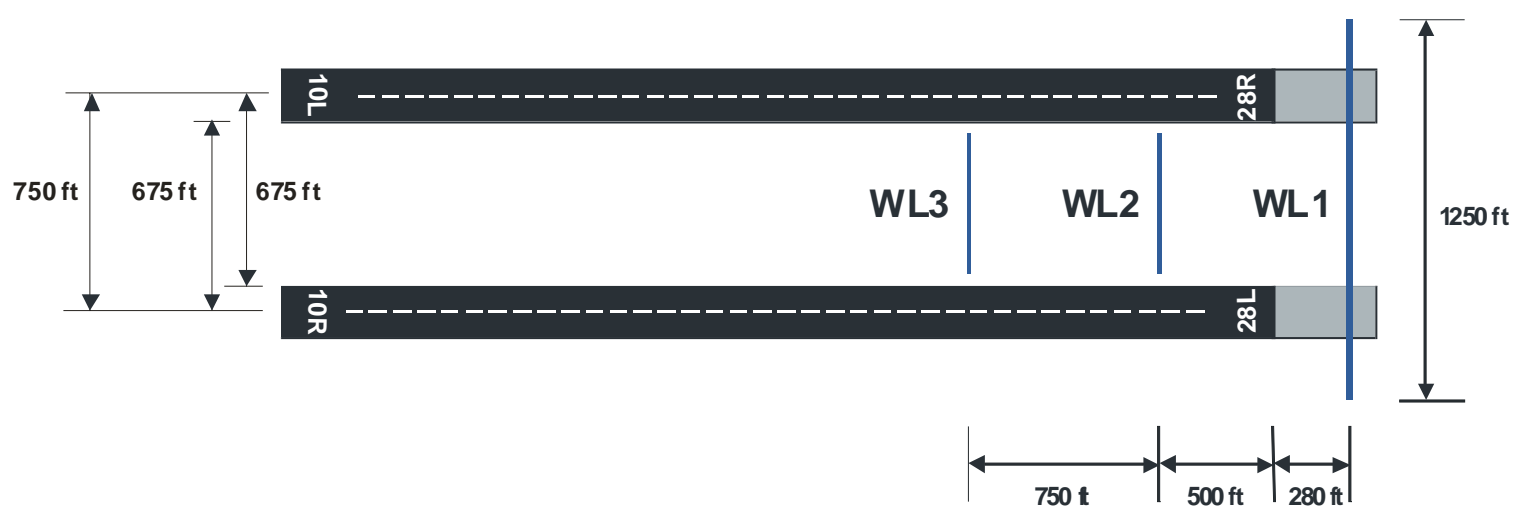

Figure 2: SFO test site.

\section{Wake Vortex Data}

The B757-200 and B757-300 wake vortex data was extracted from the second data collection period at SFO and studied in detail. This dataset contained 17,486 B757-200 vortex tracks and 302 B757-300 tracks. These are shown in Fig. 3 as they were detected on Windline 1; the figure shows the lateral position of the wake every 2 seconds for its duration. The tracks are defined as downwind and upwind; the downwind vortices are represented by triangles and the upwind vortices by circles. The B757-200 data is shown using the symbol outline; the B757-300 data is shown using the darker, filled symbols.

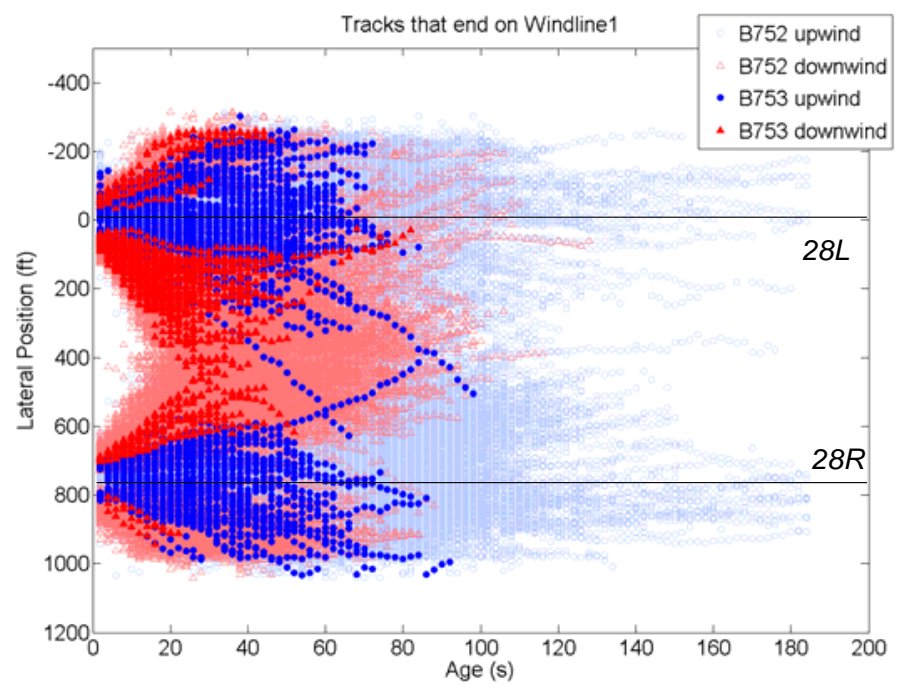

Figure 3: B757-200 and B757-300 vortex tracks.

At first glance, Fig. 3 raises the question of why the B757-300 vortex tracks appear to last for a shorter period of time. In comparing other factors in the dataset such as wind values (see Fig. 4) it is clear that the tracks were subjected to different atmospheric conditions. ASOS is the Airport Surface Observation System; the winds are measured using an ultrasonic anemometer at a height of $33 \mathrm{ft}$ and located to the right of Runway 28R near its midpoint. 

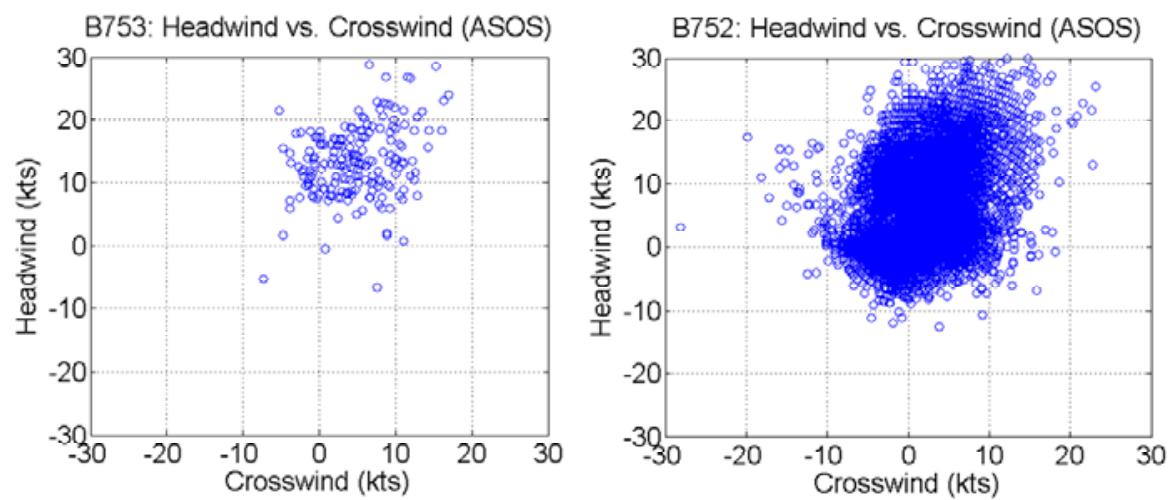

Figure 4: B757-300 and B757-200 winds.

The crosswind and headwind during the B757-300 arrivals were generally positive, whereas the B757-200 arrivals occurred under a greater variety of wind conditions with a concentration in lower magnitude crosswind and headwind values. To ensure the B757-300 dataset was an accurate representation of B757 wake behavior, the B757200 data was split into subsets of 302 vortex tracks with wind values and time-of-day values corresponding to those in the B757-300 dataset. Each subset yielded similar results.

The B757-300 dataset was plotted with the B757-200 subset under matching wind conditions; the results are shown in Fig. 5. In this scenario, the wake vortices for the B757-200 and B757-300 behave quite similarly. B757300 tracks were laid over the B757-200 tracks and both appear to fall within the same bounds. The average detected wake age for both datasets was 43 seconds. The maximum wake age for the B757-200 was 132 seconds, 98 seconds maximum for the B757-300. The maximum lateral transport was 730 feet for the B757-200 and 625 feet for the B757-300.

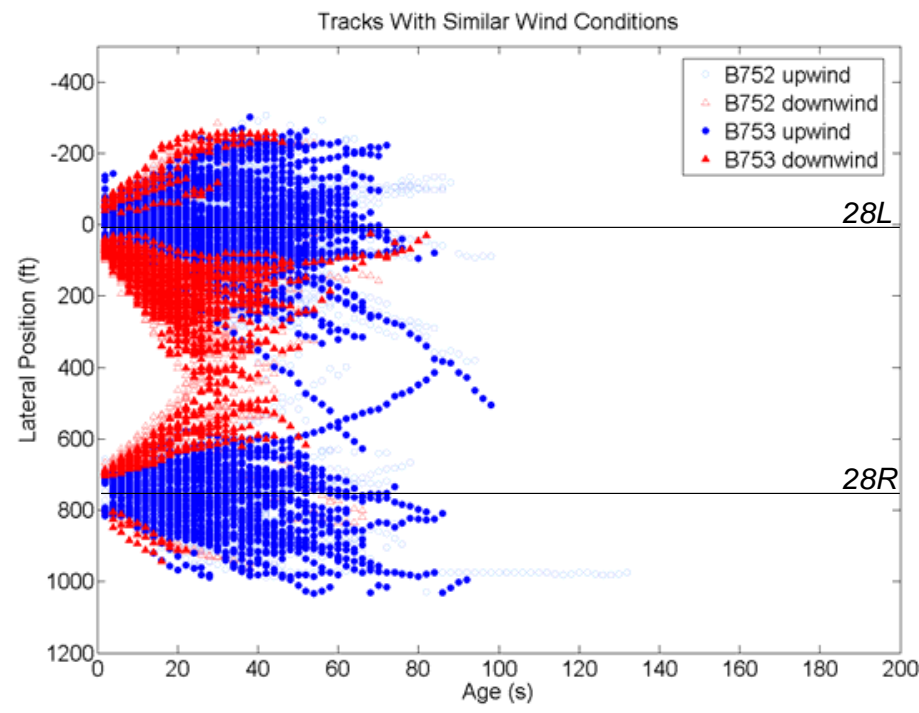

Figure 5: B757-300 and B757-200 vortex tracks with matching winds.

In Fig. 6, the maximum age for each vortex is plotted according to the measured crosswind at the time of arrival. The crosswind values shown are those reported by the airport (ASOS) when available or else it is the averaged crosswind and headwind values measured on meteorological poles located at the SFO test site on either end of Windline 1. These poles were each 20 feet tall and equipped with three propeller anemometers oriented to measure crosswind, headwind and vertical wind. Wakes generally have a longer duration under lower crosswind. Also, the 
downwind vortex being carried away by the ambient wind tends to dissipate faster. Both the B757-300 and B757200 show similar trends in downwind and upwind maximum wake age under the same ambient conditions.

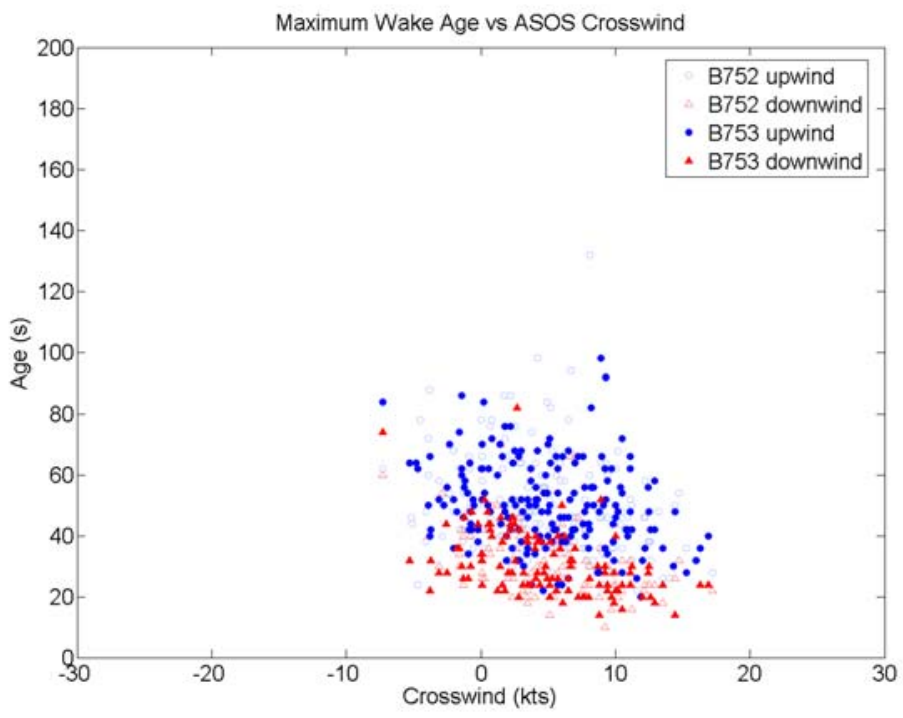

Figure 6: Maximum wake age and corresponding crosswind.

The B757-200 data was also subdivided to include only 302 tracks that were detected during the same time of day as the B757-300 tracks. These are shown in Fig. 7. Approximately 70\% of the B757-300 landings occurred between 6 and $8 \mathrm{pm}$ local time. Whenever possible, B757-200 tracks were chosen at the same day and hour of the corresponding B757-300 tracks, or else the closest day with the same hour was chosen. Again, the B757-300 tracks fell within the bounds of the B757-200 tracks although the B757-200 tracks tend to last slightly longer. The average wake age for the B757-200 in this subset was 50 seconds and 43 seconds for the B757-300. This might be attributed to the lower crosswind values during the B757-200 arrivals (See Fig. 8).

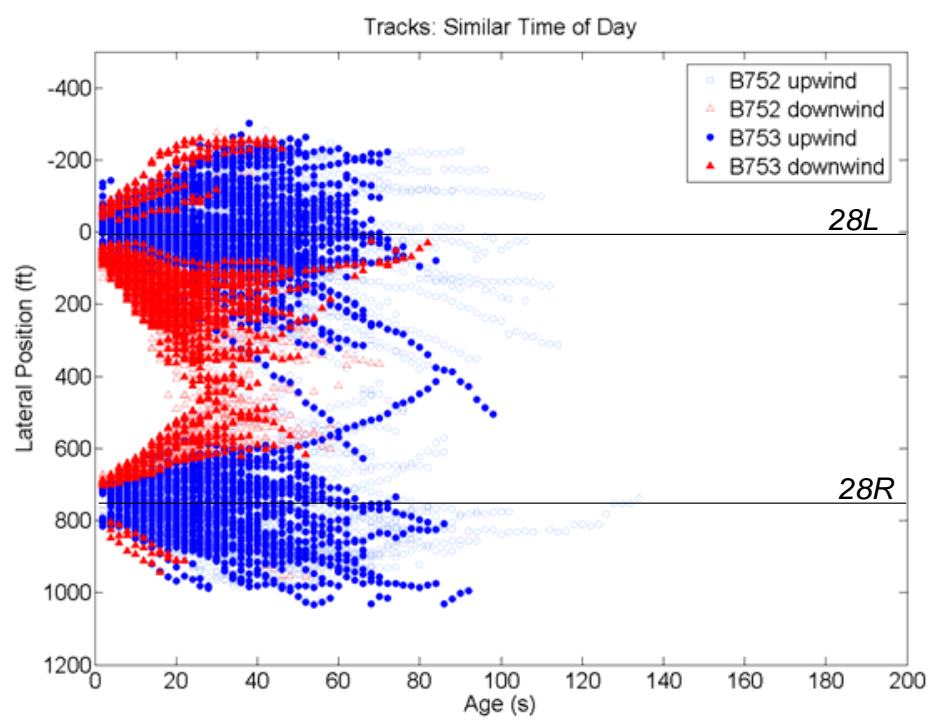

Figure 7: B757-200 and B757-300 wake vortex tracks. 

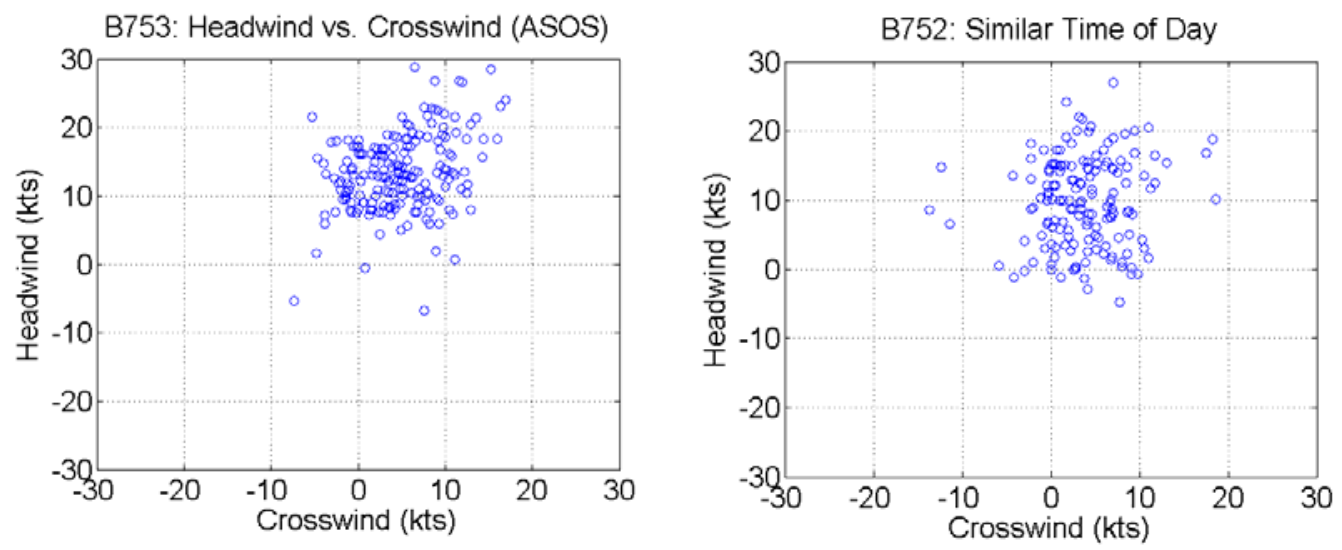

Figure 8: B757-200 and B757-300 crosswind and headwind values - similar time of day.

The lateral transport of these vortices was also studied in search of a significant difference that would warrant the classification of the B757-300 as a Heavy aircraft. For the time-of-day subset, the B757-200 maximum lateral transport was plotted with respect to the maximum wake age and the corresponding values of the B757-300 tracks were laid over this plot. The results are shown in Fig. 9. Once again, the B757-300 falls within the bounds of the B757-200 dataset. The average lateral transport of the B757-200 was $192 \mathrm{ft}$ compared to $142 \mathrm{ft}$ for the B757-300.

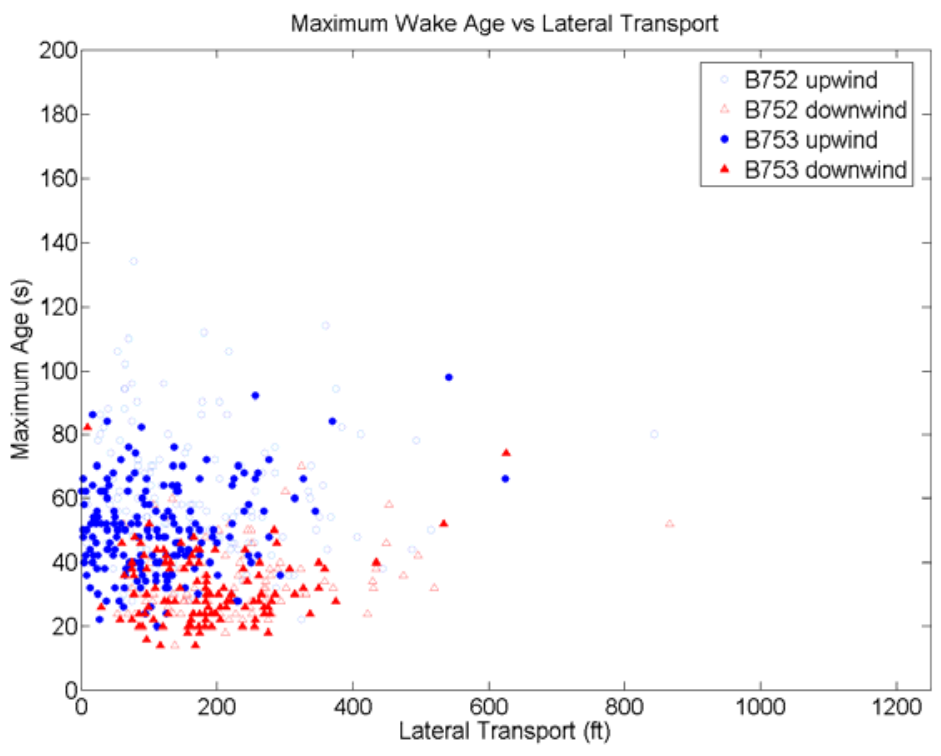

Figure 9: Lateral transport versus maximum wake age.

\section{Comparison to Other Aircraft}

In this section, the decay of B757-200 and -300 vortices are compared to the decay of vortices from other aircraft. The intent is to examine whether the B757-300 vortices behave more like Heavy aircraft vortices (as it is currently classified), B757-200 vortices, or Large aircraft vortices. Data for B737, A320, A300, B767, and B777 aircraft were obtained from the same SFO database used in Section II. The B737 and A320 are Large aircraft and the A300, B767 and B777 are Heavy aircraft. 
Figure 10 shows the cumulative probability curves for the downwind vortex for the various aircraft. The downwind vortex is the vortex moving slightly faster than the crosswind and would be the first vortex to reach a parallel runway; the upwind vortex moves slightly slower than the crosswind (and is the vortex which could stall near the runway) and be the second vortex to reach a parallel runway if the crosswind component is strong enough. To read the graphs, look at the curve formed by the solid diamonds (the B757-300 or B753 curve) at 30 seconds. This point has a cumulative probability of 0.4 which means that $40 \%$ of the downwind B757-300 vortices lasted 30 seconds or more. At one minute at least 30\% of the Heavy B777 and B767 downwind vortices are still observed whereas less than $10 \%$ of the B737, A320, A300 and B757 downwind vortices are observed. There were only 55 A300 downwind vortices compared to several hundred cases for the other aircraft. This might explain its low probability at low ages. However, there are a few cases above 90 seconds which puts the A300 back into the Heavy aircraft region. The downwind vortices of the B757-300 behave more like the Large aircraft vortices.

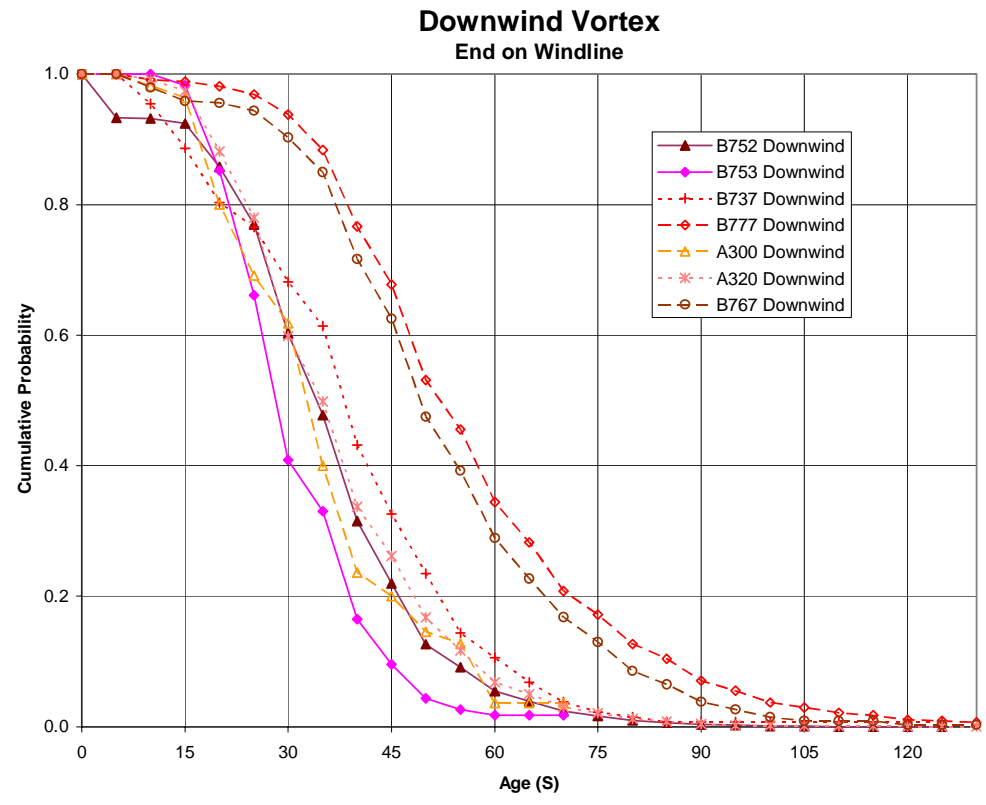

Figure 10: Cumulative probability - downwind vortex.

Figure 11 shows the cumulative probability curves for the upwind vortex for the various aircraft. Now the curves cluster more than they did for the downwind case. The ordering at 90 seconds, moving from larger cumulative probability to smaller cumulative probability is: B777, B767, A300, B757-200, A320, B737 and B757-300. The A300/B757-200 and A320/B737 curves appear to be on top of each other at 90 seconds and the specific probability values had to be checked to separate them. Note that, as in the downwind case, the A300 upwind vortices did last longer than the B757-200 upwind vortices as can be seen at 120 seconds age. There were only 88 A300 upwind vortices. 


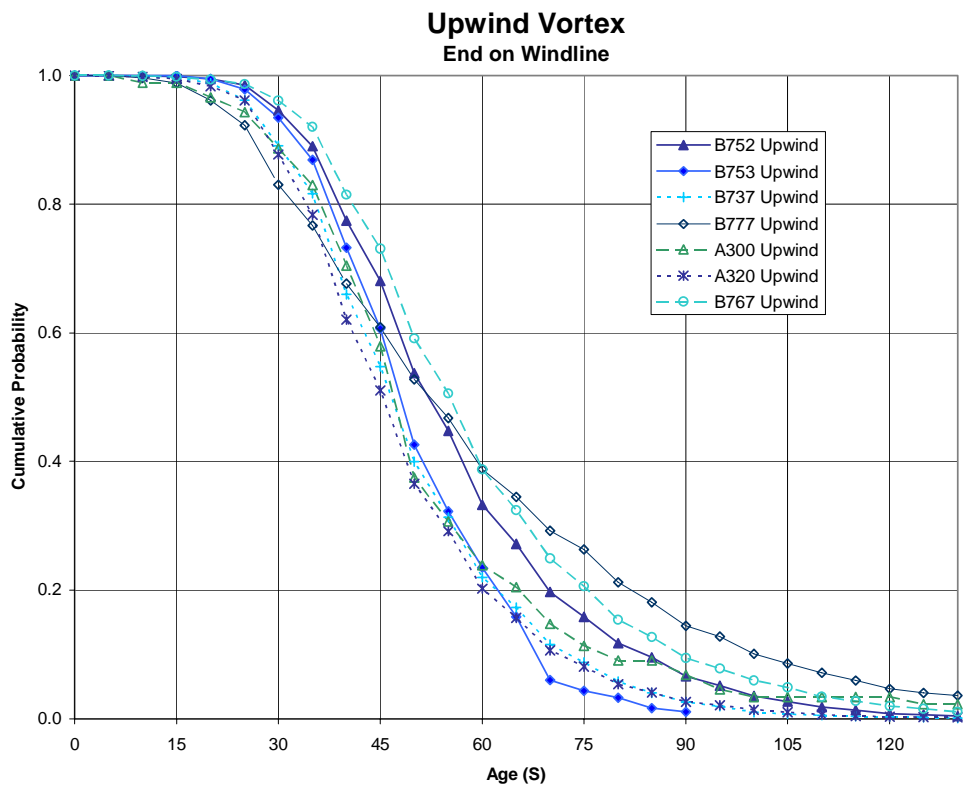

Figure 11: Cumulative probability - upwind vortex.

The primary outcome of this comparison is that the B757-300 vortices, from a wake vortex lifetime standpoint, behave like Large aircraft vortices rather than Heavy aircraft vortices. In addition, the B757-300 vortices exhibit shorter average lifetimes compared to the B757-200 vortices.

\section{Effect of Weight on Vortex Decay}

The SFO data has shown that the vortices of the heavier B757-300 decay somewhat faster than the vortices of the B757-200. Based on a simple model of wake vortices, this result is not surprising.

After the wake rollup process is complete, an aircraft wake can be described as two counter rotating, axially symmetric line vortices. Each vortex can be characterized by its tangential velocity profile $v(r)$, where $r$ is the distance from the vortex center. The circulation profile $\Gamma(\mathrm{r})$ can be calculated from the velocity profile:

$$
\Gamma(r)=2 \pi r v(r) .
$$

As the vortex radius $r$ increases, the circulation approaches an asymptotic value:

$$
\Gamma=M g / K \rho V b
$$

where $\mathrm{M}$ is the aircraft mass, $\mathrm{g}$ is the acceleration of gravity, $\mathrm{K}$ is the wing loading factor ( $\mathrm{K}=1$ for uniform loading and $\mathrm{K}=\pi / 4$ for elliptic loading), $\rho$ is the air density, $\mathrm{V}$ is the airspeed, and $\mathrm{b}$ is the wingspan. The lift coefficient, $\mathrm{C}_{\mathrm{L}}$, is given by:

$$
C_{L}=L / q S
$$

where $\mathrm{L}$ is the lift, $\mathrm{q}=(1 / 2) \rho \mathrm{V}^{2}$ and $\mathrm{S}$ is the wing platform area. Thus,

$$
C_{L}=M g /(1 / 2) \rho V^{2} S
$$

or, rearranging the terms,

$$
\rho V^{2}=M g /(1 / 2) S C_{L} .
$$


On approach, aircraft are operated typically with a constant lift coefficient so that

$$
\rho V^{2}=(\text { constant }) M g=k M g
$$

and Eq. (2) becomes

$$
\begin{aligned}
& \Gamma=M g / K \rho(k M g / \rho)^{1 / 2} b \\
& \Gamma=(M g)^{I / 2} / K \rho^{I / 2} k^{1 / 2} b .
\end{aligned}
$$

The timescale for wake vortices is expressed in normalized form, $\mathrm{T}$, based on the time for the vortex pair to descend one initial vortex spacing, $\mathrm{b}_{0}$, at an initial descent speed of $\mathrm{w}$ :

$$
\begin{aligned}
& T=b_{0} / w=2 \pi b_{0}^{2} / \Gamma \\
& T=2 \pi K^{3} b^{3} k^{1 / 2} \rho^{1 / 2} /(M g)^{1 / 2} \\
& T=(\text { constant }) /(M g)^{1 / 2}
\end{aligned}
$$

This simple model shows that the time for complete vortex decay (typically 5 to 8 units) is inversely proportional to the square root of the weight $\mathrm{Mg}$ of the aircraft. Therefore, for a given wingspan $\mathrm{b}$, on approach the heavier aircraft is expected to decay faster than the lighter aircraft; the B757-300 vortices are expected to decay faster than the B757-200 vortices, which is what was observed in this study.

\section{Conclusion}

The capacity of the large airports is becoming more and more constrained. The wake vortex separation standards limit the number of aircraft operations in instrument conditions. Thus, it is imperative that these standards be safe, first of all, and yet not be overly conservative.

The B757-300 is a stretched version of the B757-200. Its maximum certificated takeoff weight is $270,000 \mathrm{lbs}$ or 20,000 lbs above the B757 wake vortex separation standard (220,000 to 250,000 lbs), thus putting it into the Heavy category $(255,001+\mathrm{lbs})$. Since the wingspan of the B757-300 is the same as the B757-200, it was expected that the vortices of the -300 series would decay faster than the -200 series and thus the B757-300 would not need to be elevated from the B757 wake vortex category into the Heavy category.

Analysis of the behavior of B757-200 and B757-300 vortices has confirmed that B757-300 vortices do indeed decay faster than B757-200 vortices. Based on this analysis, the B757-300 need not be treated on approach/landing as a Heavy aircraft. Re-categorizing the B757-300 back into the B757 wake category will regain $1 \mathrm{nmi}$ for B757, Large and Small aircraft following the B757-300. This action will have a positive effect on capacity, especially at those airports frequented by B757-300 operations.

\section{References}

1. Burnham, D. C. and Hallock, J. N., "Wake Vortex Separation Standards: Analysis Methods," DOTVNTSC-FAA-97-04, May 1997.

2. NTSB ID SEA93GA041, Cessna 550 Citation, Billings, MT, Dec. 9, 1993.

3. NTSB ID LAX94FA073, Israel Aircraft Industries 1124A, Santa Ana, CA, Oct. 6, 1994. 